\title{
Methodology in Ancient History: Reconstructing the Fall of Samaria Heather Gerow
}

\begin{abstract}
:
Any reconstruction of a complete narrative of the fall of Samaria must rely on some educated guesswork. The evidence we have is flawed and full of holes, which makes reconstruction very difficult. One can mitigate these problems with scholarly, such as a thorough knowledge of the languages of the primary sources and the history and culture of the Ancient Near East, a broad interdisciplinary approach, and awareness of one's own biases. This paper examines methodologies of using classical sources to reconstruct ancient history.
\end{abstract}

Any attempt to understand the fall of Samaria is fraught with complications and controversy as the only written sources available are biased and either fragmentary or written long after the fact. Archaeological evidence appears to offer objective facts, but archaeological data must be interpreted and so is also potentially biased. The evidence is scarce and there is no scholarly consensus on how the fall of Samaria should be reconstructed. ${ }^{121}$ Some revisionists have suggested that reconstructing the fall of Samaria is impossible. ${ }^{122}$ They do raise some valid concerns about the evidence that need to be addressed, but these problems are not insurmountable. The evidence we have is flawed and full of holes, which makes reconstruction incredibly

121 William G. Dever, What Did the Biblical Writers Know and When Did They Know It? (Grand Rapids: William B. Eerdmans Publishing Company, 200I), 2.

122 Dever, 4. 
difficult, but not impossible. One can mitigate these problems with the tools a scholar has at his or her disposal, such as a thorough knowledge of the languages of the primary sources and of the history and culture of the Ancient Near East, as well as a broader interdisciplinary approach, and awareness of possible bias. Though it may not be possible to reach a consensus on the entire narrative of the fall of Samaria, with careful attention to the evidence and to methodology, there are some events of which we can be sure.

The Hebrew Bible is one of the most complete and detailed sources of data for the fall of Samaria. ${ }^{123}$ Unfortunately, there are problems with using the Bible as a source. It occasionally contradicts itself and many historians agree that the Bible was written long after the events it records. ${ }^{124}$ The books of Kings and Chronicles, which record parts of the narrative of the fall of Samaria, may have been written hundreds of years after the fact. ${ }^{125}$ This delay means that the Bible is both a primary and secondary source. Because of the nature of ancient history, texts written hundreds of years after the

\footnotetext{
123The Hebrew Bible will hereinafter be called the Bible for brevity's sake. No mention will be made of the New Testament, so there should be no confusion. 124 Williamson points out that the chronology given in Kings is not internally consistent. H. G. M. Williamson, ed., Proceedings of the British Academy 143: Understanding the History of Ancient Israel (New York: Oxford University Press, 2007), 324.

125 Williamson, 313, 3I5. Dever, however, argues for earlier dates. Dever, 270.
} 
events are the closest things to primary sources that are available as very few written documents have survived the ravages of millennia. Therefore, these works are considered primary sources even though they should technically be considered secondary sources. After all, the authors of the biblical books had interpreted the events they put forward, making logical deductions and guesses to fill in the holes in their information. ${ }^{126}$ Any discussion of the Bible must take into account the way the Bible interprets and presents history because ancient history did not operate under the same standards as modern history. Our modern standards of history, our focus on analysis of verifiable historical events and our reliance on written sources, are a very recent development. ${ }^{127}$ With ancient historiography, "we know that the work in question may include reports of past events (i.e. of events that actually occurred) as well as myths, legends, and hearsay, and that the historiographer felt free to embellish the sources without any research (read, e.g., Josephus, Chronicles, Jubilees, and 2 Maccabees)." 128 Therefore, the Bible needs corroboration as a primary source, and it needs to

126 Williamson, 318.

127 Williamson, 309. The exception to this is a more recent redevelopment of oral history, which is incredibly valuable, but also only possible for events within the lifetimes of living people.

128 Philip R. Davies, "Method and Madness: Some Remarks on Doing History with the Bible," Journal of Biblical Literature I I4, no. 4 (1995): 70 I. 
be treated with great caution as a secondary source. $^{129}$

Though their research is still not up to modern standards, the authors may well have had older sources at their disposal, though we have no way of knowing for certain how accurate those sources were. $^{130}$ There are indications that at least some of these sources were accurate. The Deuteronomistic historian, who is thought to have written the theologically similar books of 1 and 2 Chronicles and Deuteronomy, may have had access to the financial records of the Temple. The Deuteronomistic historian often mentions when the palace or the Temple is looted, and some of the amounts of money taken that the author gives have been verified by external sources. Access to Temple or palace financial records would explain this accuracy. ${ }^{131}$ They may also have had access to a reliable oral tradition. ${ }^{132}$ Because of this use of older sources, only some of which can be shown to be accurate, entire books of the Bible cannot be

\footnotetext{
129 Dever, 10, 271.

130 Both Dever and Williamson argue that there is evidence the authors of Kings and Chronicles had access to sources of their own that we do not have. Dever, 279-280. Williamson, 3/4. Israel Finkelstein and Neil Asher Silberman, The Bible Unearthed: Archaeology's New Vision of Ancient Israel and the Origin of Its Sacred Texts (Toronto: The Free Press, 200I), 222.

131 Williamson, 320-322.

132 Dever and Williamson argue for the possibility that oral traditions in oral cultures could hand down information far more accurately and consistently than we assume. Dever, 280; Williamson, 3 I4.
} 
weighed as a whole, but rather each portion of the text must be weighed on its own merits. ${ }^{133}$ Some of the information the Bible supplies may be quite accurate, but determining which material is accurate is difficult.

Kings and Chronicles show us one specific perception of history: both were written from the perspective of Judah, not Israel, thus they tend to favor Judah, and both show a tendency to editorialize and explain history in terms of adherence to the cult of Yahweh. ${ }^{134}$ Their purposes are primarily ideological and theological, not historical: each king, of Israel or of Judah, was judged as good or evil based mainly on who or what he worshipped, not on the basis of the astuteness of his political judgment. ${ }^{135}$ Therefore, a historian cannot rely on these books' judgment of monarchs. ${ }^{136}$ One must attempt to look beyond their characterizations of the rulers to their narratives of the kings' reigns where a historian may find some useful information. Also, many historical records with an obvious bias cannot be trusted to be accurate

\footnotetext{
133 Williamson, 33I.

134 Williamson, 307, 319; Keith Whitelam, "Recreating the History of Israel," Journal for the Study of the Old Testament 35 (1986): 52; Finkelstein and Silberman, 223. 135 Williamson, 316 ; Finkelstein and Silberman suggest that Kings and Chronicles may also evaluate the Israelite Kings on whether they collaborated with Assyria. Those who did collaborate with Assyria are described as evil. Those who did not collaborate are praised as good. Finkelstein and Silberman, 206.

136 Whitelam, 5I.
} 
when it comes to the main points of their argument, but the incidental details they provide can be quite accurate. ${ }^{137}$

In addition to those concerns already raised for Kings and Chronicles, use of the prophets as a historical source has its own unique problems. ${ }^{138}$ The prophets, such as First Isaiah and Hosea, are considered to have written during the period of growing Assyrian domination over the Northern Kingdom. ${ }^{139}$ However, their writings do not always clearly refer to one historical event or another. ${ }^{140}$ They frequently need to be interpreted in order to fit with any narrative of the fall of Samaria. They are also highly exaggerated and edited; they should only be used as a historical source with extreme caution. ${ }^{141}$

Another collection of valuable primary sources for the fall of Samaria are the Assyrian inscriptions, such as Sargon II's Great Summary Inscription and the Nimrud Prism. ${ }^{142}$ The inscriptions are the official

137 Williamson, 322.

138 Williamson, 306.

139 Roger Tomes, "The Reason for the Syro-Ephraimite War," Journal for the Study of the Old Testament 59 (Summer 1993): 69. J. Maxwell Miller and John H. Hayes,

"The Era of Assyrian Domination: The End of the Kingdom of Israel," in A History of Ancient Israel and Judah, 2nd ed. (Louisville: Westminster John Knox Press, 2006),

36I-363.

140 Tomes, 69.

141 Williamson, 306.

142 K. Lawson Younger, Jr., "The Fall of Samaria in Light of Recent Research,"

Catholic Biblical Quarterly 6I, no. 3 (July 1999): 469-470. 
royal records of the kings. No historian has doubted their usefulness based on chronological distance from the events they record. ${ }^{143}$ They can provide corroboration for some of the events described in the Bible, such as which kings of Israel were required to pay tribute and how much, as well as providing new independent information. As such, they are an invaluable independent primary source. However, these records have other flaws. The Assyrian inscriptions did not survive thousands of years unscathed and some of the inscriptions, or portions thereof, are now illegible. This means that, in order to reconstruct the entire text, one must guess at what was once written on the now damaged parts. Sometimes the missing words seem fairly obvious, given the context of the inscription and surviving letters surrounding the gap. In other areas, much larger sections are missing and it becomes impossible to do any accurate reconstruction. There is also some controversy over how exactly to reconstruct some of the texts. For example, in the Eponym Chronicle for the year 728 (during the reign of Shalmaneser $\mathrm{V}$ ), it was previously thought that Damascus was mentioned, as the letters $\mathrm{Di}$ remained intact. ${ }^{144} \mathrm{Di}$ or Dim would

\footnotetext{
143 Presumably, these inscriptions were written very soon after the events they describe. At least, none of the nineteen articles and books I read said otherwise. If there is a suggestion these sources are late, I am unaware of it.

144 Obviously, the letters are actually in cuneiform, but I have used the letters that Younger, Jr. provides in our alphabet. Younger, Jr., "The Fall of Samaria," 463.
} 
be consistent with the Assyrian spelling of Damascus. However, theologian K. Lawson Younger, Jr. points out a newer edition of the Chronicle has $\mathrm{Hi}$. This is inconsistent with the spelling of Damascus, and so he argues it must refer to a different city. ${ }^{145}$

The Assyrian inscriptions were the official documentation of the king's reign, and were presumably commissioned by the king or by a member of his court or staff. ${ }^{146}$ Conquests and victories may be exaggerated and failures would certainly not have been recorded in great detail. The inscriptions do not represent a complete history of a king's reign. On the contrary, they only preserve isolated events, usually in a positive light. They can also contradict each other. For example, the Khorsabad Annals of Sargon II say he conquered Samaria during his first regnal year, but all the other inscriptions from his reign say he conquered Samaria during his second regnal year. ${ }^{147}$

The Babylonian Chronicle from this time period is usually grouped with the Assyrian inscriptions as a

145 Younger, Jr., "The Fall of Samaria," 463.

146 Williamson, 307.

147 Brad E. Kelle, "Hoshea, Sargon, and the Final Destruction of Samaria: A

Response to M. Christine Tetley with a View Toward Method," SJOT I7, no. 2 (2003): 240. 
primary source. ${ }^{148}$ It also provides corroboration for certain kings in the Bible, as well as providing new information of its own. However, it was not written until the fourth century, giving only a few events from each king's reign. ${ }^{149}$ For example, the entry for the reign of Shalmaneser $\mathrm{V}$ only mentions the year he took power, the claim that he ravaged Samaria, and the year that he died. ${ }^{150}$ However, H. G. M. Williamson, a professor of Hebrew, suggests that "we must use sources very carefully, but should not give up on the possibility of using sources, including literary sources, to recreate ancient history." 151

Archaeological evidence is also problematic as it can be sparse and disconnected. One cannot expect a clear and complete narrative to emerge from physical objects and pieces thereof because archaeological evidence needs to be interpreted in order to be useful. This means that it, too, can be biased. ${ }^{152}$ Different archeologists may propose vastly different interpretations for the same objective

\footnotetext{
148 However, as per my previous argument concerning the Bible, it is still considered a primary source

149 Gershon Galil, "The Last Years of the Kingdom of Israel and the Fall of Samaria," Catholic Biblical Quarterly 57, no. I (January 1995): 53.

150 Brad E. Kelle, "What's in a Name? Neo-Assyrian Designations for the Northern Kingdom and Their Implications for Israelite History and Biblical Interpretation," Journal of Biblical Literature I2I, no. 4 (Winter 2002): 662-663. Younger, Jr., "The Fall of Samaria," 46I. Nadav Na'aman, "The Historical Background to the Conquest of Samaria (720 BCE)," in Ancient Israel and Its Neighbours: Interaction and Counteraction, Collected Essays, vol. I (Winona Lake: Eisenbrauns, 2005), 83. Galil, "The Last Years of the Kingdom of Israel," 55.

151 Williamson, 307.

152 Provan as cited in Davies, 699.
} 
evidence. Additionally, there may be delays in publishing the archaeological evidence. Therefore, it may be years before a discovery is known among the general academic community, and so the most recent archaeological evidence is not included in the scholarship of other disciplines. ${ }^{153}$

Archaeological evidence does, however, offer important corroboration for events narrated by textual sources (in this case, the Bible and the Assyrian inscriptions). ${ }^{154}$ It can also provide new evidence independent of written sources. For example, archaeology suggests that Israel had been attacked and pillaged by Assyria before any attack mentioned in the Bible. ${ }^{155}$ It is contemporary with the events to which it relates, though its interpretations are not. A potsherd is a potsherd. The different interpretations may be applied to the evidence, but the evidence cannot speak for itself. In addition to this, new archaeological discoveries are being made all the time. This provides scholars with even more data to analyze.

In addition to all the difficulties with each different category of evidence for generating the narrative of the fall of Samaria, more complications arise when

153 Whitelam, 63.

154 Dever, 267-270. Williamson, 318.

155 Finkelstein and Silberman, 203. 
all that evidence is compared. ${ }^{156}$ For example, Sargon II has eight different inscriptions claiming he conquered Samaria, but the Bible and the Babylonian Chronicle seem to attribute the fall of Samaria to Shalmaneser $V .{ }^{157}$ There are sites in Israel that written sources say were conquered by the Assyrians that do have Assyrian artifacts present, but none of the damage one would expect to see after conquest. ${ }^{158}$

The problematic evidence used to reconstruct the fall of Samaria is not the only impediment. Reconstruction can also be complicated by the biases and predispositions of the scholar. Any study of the history of Israel touches on the Bible, a religious document. Religious beliefs are powerful forces in the lives of humans. No matter what a scholar's specific beliefs are, be they, for example, Jewish, Christian, Hindu, agnostic, or atheist, those beliefs could affect the conclusions that are drawn. ${ }^{159}$ A Christian or Jewish scholar, for instance, might be more inclined to trust what the Bible says,

\footnotetext{
156 Dever, 27 I.

157 The Babylonian Chronicle says that Shalmaneser V ravaged Samaria -though this does not have to mean conquer. Younger, Jr., "The Fall of Samaria," 462.

Shalmaneser $V$ is the only king mentioned in the Bible in association with the fall of Samaria. However, Shalmaneser is specifically mentioned as attacking Hoshea and demanding tribute. The king of Assyria who conquered Samaria is not actually named in Kings. See 2 Kings 17. 2 Kings I8:9 attributes the fall of Samaria to Shalmaneser, but $\mathrm{Na}$ 'aman argues that this may be a later editorial addition. Na'aman, 88.

158 Younger, Jr., "The Fall of Samaria," 474.

159 Davies, 704.
} 
favoring that it over other sources when they disagree. ${ }^{160}$ On the other hand, an agnostic or atheist scholar might be less inclined to trust what the Bible says, dismissing that source even in places where many others believe the evidence is sound. The latter is not considered to be as much of a problem, but, when taken too far, it completely dismisses one of the main sources for the fall of Samaria, which could negatively affect scholarship. Many scholars are aware of their possible predispositions and acknowledge that in their work, but not all do. ${ }^{161}$ Therefore, anyone attempting to reconstruct the fall of Samaria must be aware of his or her own possible biases. That way he or she can identify those biases and acknowledge that it is impossible to be objective.

Once all the problems with reconstructing the fall of Samaria have been described, it seems a daunting task. However, there are many mitigating factors that can aid the scholar in producing a reasonably clear and accurate narrative of the event, including tools and techniques that scholars already have at their disposal. One of these mitigating factors to which scholars have access is a thorough mastery of the languages of the primary sources. It is

\footnotetext{
160 Most, though certainly not all, Christians and Jews hold the Bible sacred. Some consider it direct revelation from God.

161 Dever and Whitelam both describe their own methodologies and criticize those who do not.
} 
obvious that meaning may be lost or changed during translation; therefore, to escape this subtle altering of the sources, the scholar must read them in the original languages. ${ }^{162}$ The necessity of learning to read a source in the original language becomes even more evident in the case of the Assyrian inscriptions. Those sources have been reconstructed themselves and some of those reconstructions are controversial.

Another factor that a scholar has to aid her or him is a thorough knowledge of the culture and history of the Ancient Near East. Though this history has also been reconstructed, sometimes controversially, it is better to be familiar with the entire controversy than just one small segment of it. In the greater context of history, there may be other events that scholars are reasonably sure of, and these can be used as context. For example, one could examine Assyria's deportation of the Israelites in light of other Assyrian deportations. ${ }^{163}$ Even though details of those other deportations may not be trustworthy, so many deportations are reported that one can analyze some of the details they appear to have in

\footnotetext{
162 This is not perfect, as many ancient languages are no longer spoken and were reconstructed from texts. We may not have all the vocabulary they would have used, but it is still better than not knowing the language.

163 Bustenay Oded argues that deportation was a common practice in the Assyrian empire from the eighth century BCE onwards. Bustenay Oded, Mass Deportations and Deportees in the Neo-Assyrian Empire (Weisbaden: Dr. Ludwig Reichert Verlag, 1979), 33.
} 
common. Knowledge of ancient culture is also essential, as ancient societies are vastly different than our own society. Ancient Near Eastern cultures are now dead, as are their languages, and they can only be known through thorough study. Events of that time can often only make sense in the culture of that time. ${ }^{164}$ Knowledge of culture can also throw light on obscure phrases and make sense of previously incomprehensible events. For example, in the Eponym Chronicle of Shalmaneser V, he is said to be "in the land" during his second reigning year. ${ }^{165}$ Knowledge of Assyrian culture makes the meaning of this phrase clear. He stayed within the empire that year and did not send the army out on long campaigns to conquer surrounding territory. ${ }^{166}$

Scholars can also draw on knowledge beyond that of their own particular discipline. They can cast a broader net in the search for evidence, using an interdisciplinary approach. ${ }^{167}$ Though most of the relevant material would be concentrated in the fields of history, archaeology, and religious studies, there could be useful data in literary studies of the

164 Dever, 6. Whitelam, 53.

165 Younger, Jr., "The Fall of Samaria," 467.

166 Younger, Jr., "The Fall of Samaria," 464. M. Christine Tetley, "The Date of Samaria's Fall as a Reason for Rejecting the Hypothesis of Two Conquests," Catholic Biblical Quarterly 64 no. I (January 2002): 59. Na'aman, 83. I acknowledge that my argument here is somewhat cyclical, but given the constraints of ancient history, there is no better way to go about it of which I am aware.

167 This has also been suggested by Whitelam, 57. 
Bible, sociology, and anthropology. ${ }^{168}$ Literary studies of the Bible must be used with care as they do not always take all of the historical evidence into account. ${ }^{169}$ They may, however, point out nuances in the text that shed new light on any historical reading of the passage. Studies of other cultures, in the fields of sociology and anthropology, must be used with extreme caution as no two cultures have the same practices and beliefs, but they can shed light on cultures of a similar level of development. ${ }^{170}$ Though "the demands and pitfalls of such an interdisciplinary approach are not to be underestimated . . . the potential rewards are immense." ${ }^{171}$ It can help fill in some of the gaps in the traditional data used in reconstructing the fall of Samaria.

The historian and scholar must rely on the rules of probability, evidence, argumentation, and confirmation. ${ }^{172}$ This means that any conclusions drawn must have supporting evidence, preferably from multiple independent sources. The unfortunate reality of the study of ancient history is that this is not always possible. Isolated events can be confirmed, but any theory that seeks to reconstruct

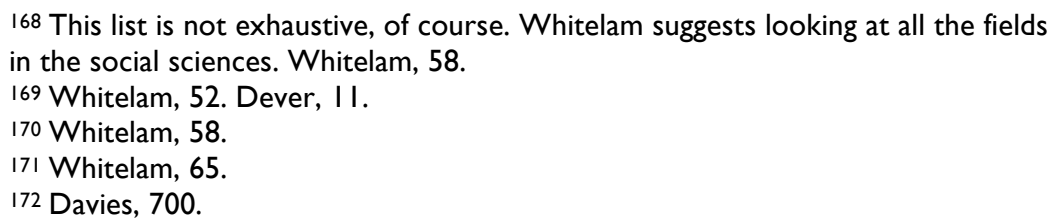


an entire narrative of the fall of Samaria must rely on "intuition; an educated imagination; and, above all, empathy." ${ }^{173}$ While archaeologist William G. Dever seems to embrace this subjectivity in ancient history, other scholars seek to rely less on hypothesis and more on what evidence is available, as

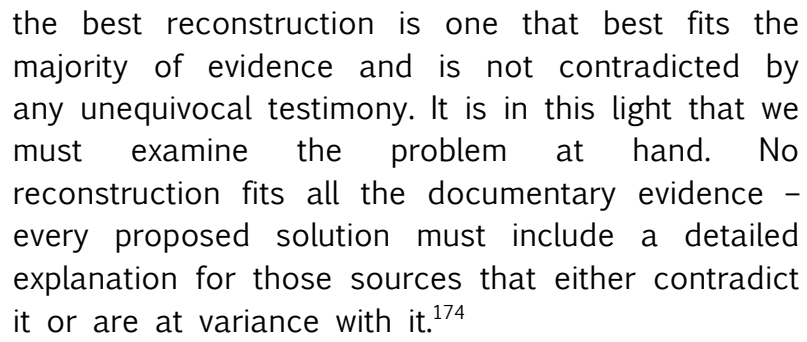

This rules out assuming errors in the text without textual evidence to support those conclusions. The scholar cannot rule evidence invalid just because it does not fit with her or his theory. ${ }^{175}$ There is, as of yet, insufficient evidence on the fall of Samaria to make all hypothesizing unnecessary, so scholars need to walk the fine line between too much hypothesizing and "worshipping the idol of false precision." 176

173 Dever, 16.

174 Na'aman, 88.

175 Kelle, "Hoshea, Sargon, and the Final Destruction of Samaria," 242.

176 Whitelam, 54. For some examples of over-simplifications of the fall of Samaria, see Finkelstein and Silberman, Miller and Hayes, and Younger Jr. They are still useful sources, but they do gloss over some of the controversies. For an example of over-precision, see Tetley. 
The historian, careful of methodology, then sifts "through all the available data, however limited and faulty they may seem, in search of facts especially those that can be established as such by 'convergences.' These convergences can be seen wherever the textual and the archaeological data, viewed independently, run along the same lines and point ultimately to the same conclusions." ${ }^{177}$ These points should accurately reflect historical reality, as far as it can ever be determined in an ancient context. The Bible, the Assyrian inscriptions, and the archaeological evidence agree that the Northern Kingdom was attacked by the Assyrians during the last quarter of the eighth century BCE. ${ }^{178}$ All three of those sources also agree that people were deported from Israel during that time period. ${ }^{179}$ The list of kings in the Bible from Ahab in the ninth century BCE to Manasseh in the seventh century and their approximate reigns can be verified by Mesopotamian sources. ${ }^{180}$ Three independent sources all point towards the same conclusion, so these are the points on which scholars can agree.

177 Dever, 295.

178 There is evidence of destruction in Israelite cities during that time period. Finkelstein and Silberman, 216.

179 See 2 Kings 17-18, the Eponym Chronicle, the Nimrud Prism, Sargon II's Great Summary Inscription, and other Assyrian inscriptions. There is also evidence that some Israelite cities were abandoned altogether during that time period. Finkelstein and Silberman, 216.

180 Williamson, 322-323. Only their approximate reigns can be verified as the specific reigns mentioned in the Bible does not add up in and of itself. Williamson, 324. 
Unfortunately, it is not possible to create an entire narrative of the fall of Samaria using only the points where the data converges in this manner. ${ }^{181}$ Those points are scarce and there are far too many instances where the data is contradictory or too sparse. At present, it seems like any reconstruction of a complete narrative of the fall of Samaria must rely on some educated guesswork. New techniques are needed to get at all aspects of the history and culture of Ancient Israel. ${ }^{182}$ Unless more evidence comes to light, or new techniques are developed, the controversy over how, exactly, Samaria fell is not likely to be resolved.

181 Williamson, 332.

182 Whitelam, 62. 


\section{Bibliography}

Davies, Philip R. "Method and Madness: Some Remarks on Doing History with the Bible." Journal of Biblical Literature 114, no. 4 (1995): 699-705.

Dever, William G. What Did the Biblical Writers Know and When Did They Know It? What Archaeology Can Tell Us about the Reality of Ancient Israel. Grand Rapids: William B. Eerdmans Publishing Company. 2001.

Finkelstein, Israel and Neil Asher Silberman. The Bible Unearthed: Archaeology's New Vision of Ancient Israel and the Origin of Its Sacred Texts. Toronto: The Free Press. 2001.

Galil, Gershon. "Israelite Exiles in Media: A New Look at ND 2443+." Vetus Testamentum 59, no. 1 (January 2009): 71-79.

---. "The Last Years of the Kingdom of Israel and the Fall of Samaria." Catholic Biblical Quarterly 57, no. 1 (January 1995): 52-65.

Kelle, Brad E. "Hoshea, Sargon, and the Final Destruction of Samaria: A Response to M. Christine Tetley with a View Toward Method." SJOT 17, no. 2 (2003): 226-244.

---. "What's in a Name? Neo-Assyrian Designations for the Northern Kingdom and their Implications for Israelite History and Biblical Interpretation." Journal of Biblical Literature 121, no. 4 (Winter 2002): 639-666.

Luckenbill, Daniel David. Ancient Records of Assyria and Babylonia: Volume I, Historical Records from Assyria, From the Earliest Times to Sargon. Vol. 1. New York: Greenwood Press. 1968.

Matthews, Victor H., and Don C. Benjamin. Old Testament Parallels: Laws and Stories from the Ancient Near East. New York: Paulist Press. 1991. 
Miller, J. Maxwell, and John H. Hayes. "The Era of Assyrian Domination: The End of the Kingdom of Israel." In A History of Ancient Israel and Judah. $2^{\text {nd }}$ ed. Louisville: Westminster John Knox Press. 2006.

Na'aman, Nadav. "The Historical Background to the Conquest of Samaria (720 BCE)." In Ancient Israel and Its Neighbours: Interaction and Counteraction, Collected Essays. Vol. 1. Winona Lake: Eisenbrauns. 2005.

Oded, Bustenay. Mass Deportations and Deportees in the Neo-Assyrian Empire. Weisbaden: Dr. Ludwig Reichert Verlag. 1979.

Paul, Shalom M. "Sargon's Administrative Diction in 2 Kings 17:27." Journal of Biblical Literature 88, no. 1 (March 1969): 226-244.

Tetley, M. Christine. "The Date of Samaria's Fall as a Reason for Rejecting the Hypothesis of Two Conquests." Catholic Biblical Quarterly 64, no.1 (January 2002): 59-77.

Tomes, Roger. "The Reason for the Syro-Ephraimite War." Journal for the Study of the Old Testament 59 (Summer 1993): 55-71.

Whitelam, Keith. "Recreating the History of Israel." Journal for the Study of the Old Testament 35 (1986): 47-70.

Williamson, H. G. M., ed. Proceedings of the British Academy 143: Understanding the History of Ancient Israel. New York: Oxford University Press. 2007.

Younger Jr., K. Lawson. "The Deportations of the Israelites." Journal of Biblical Literature 117, no. 2 (Summer 1998): 201-227.

---. "The Fall of Samaria in Light of Recent Research." Catholic Biblical Quarterly 61, no. 3 (July 1999): 461-482. 